\title{
Os efeitos dos dentes supranumerários: Complicações, Diagnóstico e Tratamento
}

\section{The Effects of Supernumerary Teeth: Complications, Diagnosis and Treatment}

\author{
Los efectos de los dientes supernumerarios: complicaciones, diagnóstico y tratamiento
}

\author{
Rafael Ricardo Renha Weiss Senise ${ }^{1 *}$, Rafael Meira Pimentel ${ }^{2}$, Gustavo Correia Machado ${ }^{3}$, Marcelo \\ Vieira Bruno ${ }^{4}$
}

Como citar esse artigo. Senise, R. R R. W; Pimentel, R. M; Machado, G. C; Bruno, M. V. Os efeitos dos dentes supranumerários: $\quad$ Complicações, Diagnóstico e Tratamento. Revista PróUniverSUS. 2021 Jul./Dez.; 12 (2): 55 59.

\section{Resumo}

Os Dentes Supranumerários são caracterizados como um distúrbio de desenvolvimento definido pela presença de um ou mais elementos dentários fora do número considerado normal. Alguns autores preferem o termo hiperdontia para descrever essa anomalia de número. A princípio, seu diagnóstico pode ser feito através da observação dentro do consultório clínico, no entanto, para uma maior precisão é necessária a realização de exames por imagem, como a radiografia panorâmica por exemplo, pois sua presença é assintomática. A etiologia não está completamente definida, sendo multifatorial. Sendo assim, o objetivo principal deste trabalho é analisar quais são os principais efeitos causados pelos dentes supranumerários, independente da dentição decídua ou permanente, apresentando, especialmente, suas complicações, diagnóstico e tratamentos adequados, com o intuito em compreender o assunto e estimular trabalhos futuros que envolvam esse tema. A metodologia do trabalho foi construída a partir de uma revisão de literatura, desenvolvendo o tema abordado através da reunião de obras que apresentaram ideias de autores que com a mesma linha de defesa do assunto.

Palavras-chave: Dentes Supranumerários; Impactação Dentária; Hiperdontia.

\begin{abstract}
Supernumerary Teeth are characterized as a developmental disorder defined by the presence of one or more dental elements outside the number considered normal. Some authors prefer the term hyperdontia to describe this number anomaly. Initially, its diagnosis can be made through observation within the clinical office, however, for greater accuracy it is necessary to perform imaging tests, such as panoramic radiography, for example, as its presence is asymptomatic. The etiology is not completely defined, being multifactorial. Therefore, the main objective of this work is to analyze the main effects caused by supernumerary teeth, regardless of the deciduous or permanent dentition, presenting, especially, their complications, diagnosis and appropriate treatments, in order to understand the subject and encourage future work that involve this theme. The work's methodology was built from a literature review, developing the topic addressed by bringing together works that presented ideas from authors with the same line of defense on the subject.

Keywords: Supernumerary Tooth; Dental Impaction; Hyperdontics.
\end{abstract}

Afiliação dos autores:

${ }^{1}$ Discente do Curso de Graduação em Odontologia da Universidade de Vassouras, RJ, Brasil. E-mail: rafael_senisee@hotmail.com ORCID: https://orcid.org/0000-0002-4693-3418. ${ }^{2}$ Docente do Departamento de Cirurgia do Curso de Graduação em Odontologia da Universidade de Vassouras, RJ, Brasil. E-mail:dr.rafaelmpimentel@gmail.com ORCID: https:// orcid.org/0000-0001-5937-6369.

${ }^{3}$ Docente do Departamento de Cirurgia do Curso de Graduação em Odontologia da Universidade de Vassouras, RJ, Brasil. E-mail: gustavocmachado@gmail.com ORCID: https:// orcid.org/0000-0002-1727-7781.

${ }^{4}$ Docente do Departamento de Prótese do Curso de Graduação em Odontologia da Universidade de Vassouras, RJ, Brasil. E-mail: mvieirabruno@gmail.com ORCID: https://orcid. org/0000-0002-9375-0868.

* Email de correspondencia: rafael_senise@hotmail.com 


\section{Resumen}

Los dientes supernumerarios se caracterizan como un trastorno del desarrollo definido por la presencia de uno o más elementos dentales fuera del número considerado normal. Algunos autores prefieren el término hiperdoncia para describir esta anomalía numérica. En un principio su diagnóstico se puede realizar mediante observación dentro del consultorio clínico, sin embargo, para mayor precisión es necesario realizar pruebas de imagen, como radiografía panorámica, por ejemplo, ya que su presencia es asintomática. La etiología no está completamente definida, siendo multifactorial. Por tanto, el principal objetivo de este trabajo es analizar los principales efectos que provocan los dientes supernumerarios, independientemente de la dentición decidua o permanente, presentando, especialmente, sus complicaciones, diagnóstico y tratamientos adecuados, con el fin de comprender el tema y fomentar futuros trabajos que involucrar este tema. La metodología del trabajo se construyó a partir de una revisión de la literatura, desarrollando el tema abordado reuniendo trabajos que presentaban ideas de autores con la misma línea de defensa sobre el tema.

Palabras clave: Dientes Supernumerarios; Impactación Dental; Hiperdoncia.

\section{Introdução}

De acordo com Santos e seus colaboradores ${ }^{1}$, os dentes supranumerários são caracterizados como dentes em excesso na arcada dentária, originando a hiperdontia, podendo estar associados a síndromes como a displasia cleidocraniana e a síndrome de Gardner, podendo ocorrer tanto na maxila como na mandíbula ${ }^{1,2,3}$.

Salienta-se, que o predomínio de dentes supranumerários acontece com maior incidência na dentição permanente do que na decídua, variando entre $0,15 \%$ e $3,8 \%$, sendo mais frequente em homens do que em mulheres ${ }^{3,4}$.

O tipo mais comum de dente supranumerário é o mesiodente, sendo capaz de ocorrer como único, múltiplo, unilateral ou bilateral. Em se tratando da sua formação morfológica, o mesiodente pode se classificar como cônico, tubercular ou molariforme, a forma cônica é a mais comum. ${ }^{3}$ Em algumas pessoas, os mesiodentes erupcionam normalmente, no entanto, podem permanecer impactados ou entrar em erupção na posição invertida, o que resulta seguir em posição ectópica ${ }^{3}$.

No que diz respeito à sua etiologia, o dente supranumerário não tem uma definição única estabelecida, aponta-se que pode ser um achado isolado, ou como parte de uma síndrome aliado à hereditariedade ${ }^{3}$.

Sendo assim, o diagnóstico recente da condição clínica na dentição decídua e mista pode evitar complicações extras ao sistema estomatognático. Por isso a importância de exames computadorizados para o caso clínico ser observado na íntegra, como as radiografias panorâmicas, oclusais e periapicais, que são recomendadas para auxiliar no processo do diagnóstico de mesiodente associado aos achados da tomografia computadorizadal ${ }^{1,3,4}$.

Portanto, é necessário que o dentista realize o diagnóstico com cautela e aptidão, para que ocorra o tratamento mais adequado a cada caso clínico analisado, incluindo tempo de cirurgia, probabilidades de complicações e um possível tratamento ortodôntico ${ }^{4}$.

Diante disso, o objetivo geral deste trabalho é analisar quais são os principais efeitos causados pelo dente supranumerário, independente da dentição decídua ou permanente, apresentando, principalmente, suas complicações, diagnóstico e tratamentos adequados, com o intuito em compreender o assunto e estimular trabalhos futuros que envolvam essa temática.

\section{Metodologia}

A metodologia do trabalho será construída a partir de uma revisão de literatura, com o intuito em desenvolver o tema abordado através da reunião de obras que acolham ideias de autores que sigam a mesma linha de defesa do assunto.

Nesse contexto, o material pesquisado foi escolhido a partir de descritores e/ou combinações de pares de palavras como "dentes supranumerários"; "complicações do dente supranumerário"; diagnóstico e dente supranumerário; tratamento e dente supranumerário.

Em seguida, para a seleção dos materiais que foram utilizados no trabalho, foi feita uma leitura superficial acerca do resumo e introdução de cada documento encontrado, dentre eles, artigos científicos, revistas on-line e trabalhos acadêmicos. Foram encontrados 42 artigos, sendo excluídos materiais que não estivessem envolvidos com o tema em questão e que apresentassem mais de 15 anos de publicação, sendo selecionados 15 trabalhos.

\section{Resultados e Discussão}

As primeiras fases da composição dentária podem originar complicações de desenvolvimento que podem 
vir a promover anomalias, dentre as quais evoluem com dentes supranumerários ${ }^{5}$.

Os dentes supranumerários são caracterizados como dentes extras em comparação à dentição normal, ocorrendo de forma isolada ou múltipla, uni ou de forma bilateral, e em uma ou ambas as mandíbulas, com forma e tamanho normalmente consistentes com a dentição na região da mandíbula onde eles são localizados ou com pouca ou nenhuma semelhança ${ }^{1,5}$.

No que diz respeito ao número e local de surgimento de dentes supranumerários, existe uma variedade relevante. Aponta-se, que eles são encontrados com maior frequência na dentição permanente do que na decídua, e, quando nela ocorrem, podem se localizar constantemente na região da pré-maxila. Estudos, em sua grande maioria, indicam a prevalência maior dos supranumerários no gênero masculino sobre o feminino $^{2}$.

Os dentes supranumerários podem ser classificados de acordo com a forma, como rudimental ou dentes suplementares; de acordo com a sua cronologia como pré-decídua, dentes semelhantes aos permanentes e pós-permanentes ou complementar; topografia como mesiodens, paramolar, distomolar e parapremolar; e orientação como vertical, invertida e transversal ${ }^{5}$.

É importante mencionar, que um dente supranumerário pode permanecer impactado por muitos anos sem complicações ou ser a causa de complicações relacionadas com erupção dentária e desenvolvimento da dentição ${ }^{5}$.

Mesiodens é o termo usado para definir o dente supranumerário que surge na maxila, entre os incisivos centrais, na região de linha média, podendo surgir como único, múltiplo, unilateral ou bilatera. ${ }^{3,6}$ Esses dentes, em especial, podem ficar irrompidos na cavidade oral ou impactados. O que resulta em uma má higienização, dificuldade ou impossibilidade de erupção dos dentes regulares e comprometimento da estética ${ }^{6}$.

Em se tratando das complicações ocasionadas pela presença do mesiodente, estas se referem ao atraso de erupção, apinhamento, impactação de incisivos permanentes, formação anormal de raízes, alteração da trajetória de erupção dos incisivos, diastema na linha média, lesões císticas, infecção intraoral, rotação, reabsorção radicular de dentes adjacentes ou até mesmo erupção na cavidade nasal ${ }^{4}$.

Os mesiodentes podem erupcionar naturalmente em algumas pessoas, entretanto, são capazes de permanecer impactados ou entrar em erupção na posição invertida, o que resulta em posição ectópica. Eles podem manifestar morfologias diferentes, tais como: cônico, tubercular ou molariforme, sendo a forma cônica a mais comum, de raiz curta e, que se encontram, na maioria dos casos, impactados ${ }^{3,6}$.

Cabe ressaltar, que o supranumerário se não for removido, pode acarretar certos efeitos deletérios para o paciente, como a reabsorção radicular do dente vizinho, maloclusão, formação de cistos, erupção ectópica, retardo, impacção ou má formação do dente permanente, diastema, entre outros, o que faz reconhecer a importância de um diagnóstico precoce e de um tratamento ideal ${ }^{2,6}$.

O diagnóstico do dente supranumerário é realizado por meio clínico-radiográfico, ou de forma mais concisa, tomografias. A tomografia computadorizada tem sido introduzida, atualmente, como procedimento complementar de diagnóstico bastante seguro e conciso para definir a localização exata do dente supranumerário. As radiografias oclusais e periapicais são de extrema importância ao diagnóstico do supranumerário na região dos incisivos. Assim, é feita a avaliação de casa caso individualmente para a conduta do tratamento ${ }^{3}$.

Radiografias periapicais, oclusais e panorâmicas são indicadas na rotina da clínica, especialmente em pacientes que manifestam distúrbios de número e posicionamento dental. A radiografia panorâmica tem como especialidade apresentar, por meio de uma projeção única, numa só imagem, diversas estruturas anatômicas ${ }^{2}$

É importante mencionar, que toda experiência clínica profissional associada ao histórico clínico de antecendentes familiares portadores de mesiodente devem ser levados em conta ${ }^{3}$.

Portanto, é aconselhável a radiografia panorâmica, oclusal e periapical para concretizar o diagnóstico do mesiodente e determinar a posição vestíbulolingual quando impactado. Afinal, quanto mais cedo o diagnóstico for concluído, as complicações como impacção dental, erupção atrasada ou erupção ectópica poderão ser minimizadas de forma mais rápida ${ }^{3}$.

Para que o prognóstico seja satisfatório, é aconselhável também a avaliação do estágio de desenvolvimento dental e a proximidade do mesiodente das raízes dos incisivos permanentes, além de considerar o risco de trauma cirúrgico e a quantidade de remoção óssea ${ }^{3}$.

Sendo assim, depois do diagnóstico estabelecido, é essencial delimitar o procedimento a ser aplicado para acarretar a erupção do dente, que pode ser tanto pela observação clínica apenas ou por meio da exposição cirúrgica com tração ortodôntica do dente, sendo esse o mais indicado.

Diante do diagnóstico da presença de um supranumerário, é necessário que cada caso seja avaliado e conduzido de forma individual. Como afirmam inúmeros autores, a remoção do mesiodente é a conduta mais indicada, até por conta dos riscos da presença do próprio mesiodente que pode vir a gerar atrasos na erupção dos dentes adjacentes. Com o intuito em prevenir possíveis danos aos germes dentários adjacentes, é aconselhável adiar um pouco mais o procedimento até que o desenvolvimento da raiz desse 
dente adjacente esteja quase completo, o que equivale a pacientes que têm idade mínima entre 8-10 anos ${ }^{3}$.

Portanto, percebe-se, que pelos materiais analisados, a grande maioria aponta a remoção cirúrgica do dente supranumerário.

Por tudo isso, infere-se, que a identificação precoce de dentes supranumerários, o planejamento do tratamento e abordagem corretos, contribuem com a preservação dos dentes e estruturas adjacentes ${ }^{5}$.

Aponta-se, que as anomalias dentárias de número acontecem com frequência. Por isso o estudo essencial dessas condições como forma de alertar sobre a importância do diagnóstico precoce na prevenção de más oclusões, tanto nas dentições decídua e mista ${ }^{7}$.

As anomalias dentárias de número podem acontecer de duas maneiras: Quando há ausência de desenvolvimento de um ou mais dentes, sendo denominada de hipodontia (agenesia de menos de seis dentes), oligodontia (ausência de seis ou mais dentes, com exceção dos terceiros molares) e anodontia (ausência de todos os dentes); é importante salientar que essas duas últimas anomalias são raras, quando há excesso do número normal de dentes, acontece a hiperdontia?

A hipodontia ocorre tanto na dentição decídua como na permanente, podendo ser denominada também de agenesia, identificada como a anomalia de desenvolvimento dentário mais comum. Ela pode estar associada a síndromes ou outras anomalias dentárias. Sua etiologia é multifatorial, tendo influência de fatores genéticos e ambientais, atingindo tanto o aspecto estético quanto o funcional, o fisiológico e o emocional ${ }^{7}$.

Cabe ressaltar, que a hipodontia pode acontecer associada a outras alterações, como atraso na irrupção, irrrupção ectópica de caninos permanentes, morfologia dentária anormal (como taurodontismo e incisivos em forma de cone), danos periodontais e falta de crescimento alveolar. Seu tratamento exige um planejamento cauteloso e multidisciplinar, que envolve, especialmente, Ortodontia, Dentística e Cirurgia ${ }^{7}$.

Em relação à hiperdontia, esta pode afetar tanto a dentição decídua quanto a permanente, chamando o dente de supranumerário. A hiperodontia pode aparecer de forma isolada ou múltipla, unilateral ou bilateral, e atingir um ou ambos os maxilares. Sua etiologia ainda não está definida, e uma das teorias é que os supranumerários se desenvolvem diante da hiperatividade da lâmina dentária ${ }^{7}$.

De acordo com a sua localização na arcada dentária, os supranumerários podem ser classificados em mesiodente, distomolar e paramolar, sendo o primeiro mais comum, que fica localizado na linha média da maxila. Esses dentes podem irromper normalmente, assumir uma posição ectópica ou, algumas vezes, não irromperem ${ }^{7}$.

Os supranumerários podem provocar complicações, como apinhamento dentário, retardo na irrupção dos dentes, deslocamento (como rotação de dente permanente), mudanças na posição dos dentes permanentes, alteração oclusal, sequência anormal de erupção dentária, apinhamento, cárie, inflamação da gengiva e abscessos periodontais alterando a oclusão e a estética. A composição de cisto odontogênico e reabsorção de dentes vizinhos são episódios mais raros relacionados à hiperdontia ${ }^{7,8}$.

O diagnóstico dos dentes supranumerários, normalmente, acontece no momento do exame clínico ortodôntico ou quando solicitados os exames complementares, como radiografias. A maioria desses dentes são impactados e assintomáticos, sem afetar os outros dentes. Os dentes supranumerários podem ocorrer inclusos ou impactados. As inclusões ectópicas aconntecem por volta de $1 \%$ da população em geral e pode estar presente em muitas localizações diversas. Por isso a importância do diagnóstico precoce, propiciando a realização do tratamento mais adequado para evitar complicações maiores, conseguindo até reduzir a complexidade do caso clínico e garantir maior sucesso $^{7,8}$.

Dentes supranumerários (ST) podem ocorrer tanto na dentição decídua como na permanente, em qualquer localização, na maxila ou mandíbula, podendo provocar diversos tipos de complicações que exigem certos tipos de abordagens no tratamento. Com questões metodológicas, bem como diferenças populacionais, os números variam, mas sua prevalência pode atingir $6 \%$, ou possivelmente ainda mais. Esta anomalia é etiologicamente heterogênea e é altamente variável, diferindo em número, localização, morfologia, relação com outros dentes ${ }^{9,10}$.

A formação dos tecidos dentários é um fenômeno complexo e delicado. O desenvolvimento de alterações dentárias pode acontecer por conta de anomalias no número, tamanho, forma, posição e estrutura dos dentes. E os dentes supranumerários são as alterações de número mais comuns e encontradas na Odontologia ${ }^{11}$.

Dentes são considerados supranumerários quando o número for superior a 20 na dentição decídua e 32 na dentição permanente. A prevalência de dentes supranumerários para dentição permanente varia de 0,5 e $5,3 \%$ e na dentição decídua entre 0,2 e $0,8 \%$ em diferentes populações ${ }^{6,7,8}$, sendo notificada com mais frequência no gênero masculino. A etiologia dos dentes supranumerários não está completamente definida, e várias teorias têm sido apresentadas para explicar o seu desenvolvimento, dentre elas, o crescimento excessivo da lâmina dentária, fatores hereditários, dicotomia do germe dentário, doenças gerais, e algumas síndromes ${ }^{11,12,13,14}$.

Várias obras mostram que muitos casos de dentes supranumerários podem estar associados a síndromes como Gardner, Ehler-Danlos, Apert, Down e Displasia 
Cleidocraniana, entre outras ${ }^{11}$.

Portanto, é possível constatar que os dentes supranumerários impactados representam um desafio para os dentistas, pois podem acarretar atraso na erupção do dente permanente, alteração do crescimento ósseo e posicionamento ectópico do dente permanente ${ }^{11,14}$.

Diante disso, os exames de imagem são fatores de grande importância no plano de tratamento em Odontologia, principalmente nos casos que envolvem estruturas em localização intraóssea nas arcadas dentárias, como acontece com frequência na hiperdontia. Dentes supranumerários podem se apresentar em íntima relação com as demais estruturas anatômicas adjacentes, como outros elementos dentários, seio maxilar, fossa nasal e canal mandibular ${ }^{15}$.

Além disso, podem apresentar variações anatômicas, e o diagnóstico por imagem se faz fundamental na visualização de tais alterações, com o objetivo de promover melhores resultados e gerar a menor morbidade possível ao paciente, durante um possível procedimento cirúrgico ${ }^{15}$.

Entre os exames de imagem escolhidos pelo dentista, a radiografia panorâmica tem sido a mais utilizada, pois produz uma ampla visualização das estruturas com baixa dose de radiação ${ }^{15}$.

\section{Conclusão}

Por tudo isso, torna-se evidente, que os dentes supranumerários podem acarretar diversas complicações, tais como apinhamento dental, diastemas, impactação de dentes permanentes, erupção retardada e/ou ectópica, rotação dentária, desenvolvimento de cistos, reabsorção de dentes adjacentes, entre outras. $\mathrm{O}$ que faz com que o diagnóstico precoce seja de grande importância para que o tratamento escolhido ocorra de maneira satisfatória, além de poder prevenir essas alterações.

Foi possível detectar ainda, que os dentes supranumerários podem irromper normalmente ou podem permanecer impactados. E sua prevalência é maior na dentição permanente, na maxila, sendo o sexo masculino o mais acometido.

A partir disso, dentre os exames de imagem mais indicados para a realização do diagnóstico, a radiografia panorâmica tem sio a mais utilizada e adequada.

Sendo assim, é importante estabelecer dois importantes fatores nesse processo: a cautela e a atuação do profissional de Odontologia para estabelecer o diagnóstico exato em relação ao dente supranumerário, e a escolha da melhor forma de tratamento indicada para cada caso.

\section{Referências Bibliográficas}

1. Santos TS et al. Multiple Supernumerary Teeth in a Nonsyndromic 12-Year-Old Female Patient - A Case Report. Brazilian Dental Journal. 2014;
25(1): 79-82.

2. Dayube AC, Pompermayer L, Neto Segundo, NP. Levantamento das anomalias dentárias de número (supranumerários) em radiografias panorâmicas de um serviço de documentação odontológica da cidade do Salvador-Bahia. R. Ci. md. biol., Salvador. 2011 jan./abr.;10(1):34-38.

3. Dias GF et al. Diagnóstico e tratamento de dentes supranumerários na clínica infantil - relato de caso. Rev. CEFAC. 2019; 21(6): e16319.

4. Azenha MR et al. Abordagem Cirúrgica de Dente Supranumerário (Mesiodens) na Região Palatina: Caso Clínico. Revista Portuguesa de Estomatologia, Medicina Dentária e Cirurgia Maxilofacial. 2007;48(1):3741 .

5. Pérez IE, Chávez AK, Ponce, D. Prevalence of supernumerary teeth on panoramic radiographs in a non-adult Peruvian sample. Int. J. Odontostomat. 2014;8(3):377-83

6. Miranda E et al. Mesiodens invertido: relato de caso. RGO, Rev Gaúch Odontol, Porto Alegre. 2016 jan./mar;64(1):83-6.

7. Torres $\mathrm{PF}$ et al. Anomalias dentárias de número em pacientes ortodônticos. Rev Odontol UNESP. 2015 Sept-Oct; 44(5): 280-4.

8. Martorelli SBF, Lacerda EPM, Andrade FBM. Microtooth supernumerary included in Zygomatic root. RGO, Rev Gaúch Odontol. 2018 Jan-Mar; 66(1):82-7.

9. Lubinsky M, Kantaputra PN. Syndromes with supernumerary teeth. Am J Med Genet. 2016; Part A 170(10): 2611-16.

10. Ribeiro MR. Dentes Supranumerários - Revisão de Literatura. (Trabalho de Conclusão de Curso). Universidade Federal do Rio Grande do Sul. Faculdade de Odontologia. Porto Alegre, 2011.

11. Stringhini Junior E, Stang B, Oliveira LB. Dentes supranumerários impactados: relato de caso clínico. REV ASSOC PAUL CIR DENT. 2015;69(1):89-94.

12. Lodi CS, Rodrigues A, Angeloni BP. Diagnóstico e tratamento de dente supranumerário incluso: Relato de Caso. Revista Funec Científica Odontologia. 2017 jul-dez;1(1):22-32.

13. Hamada MH et al. Prevalência de dentes supranumerários em pacientes que procuraram tratamento ortodôntico. Arch. Oral Res. 2011;7(2):141-16.

14. Bezzerra PKM, Cavalcanti AL. Dentes supranumerários: revisão da literatura e relato de caso. R. Ci. méd. biol. Salvador, 2007 set./dez.:6(3): 349-56.

15. Valente NA. A importância da TCFC no diagnóstico e localização de dentes supranumerários. Rev. bras. odontol. 2016 set./dez.;73(1): 55-9. 